\title{
Melasma, Melasma-Like Lichen Planus Actinicus, and Butterfly Lichen Planus Actinicus Build up One Spectrum (Clinico-Histopathological Study)
}

\author{
Khalifa E. Sharquie ${ }^{1,2^{*}}$, Adil A. Noaimi1,2, Maha A. Al-Shukri3 \\ ${ }^{1}$ Department of Dermatology, College of Medicine, University of Baghdad, Baghdad, Iraq \\ ${ }^{2}$ Arab Board for Dermatology and Venereology, Baghdad Teaching Hospital, Medical City, Baghdad, Iraq \\ ${ }^{3}$ Department of Dermatology, Baghdad Teaching Hospital, Medical City, Baghdad, Iraq \\ Email: ksharquie@ymail.com, adilnoaimi@yahoo.com, dr.mahaameer2012@gmail.com
}

Received 10 June 2015; accepted 7 September 2015; published 10 September 2015

Copyright (C) 2015 by authors and Scientific Research Publishing Inc.

This work is licensed under the Creative Commons Attribution International License (CC BY). http://creativecommons.org/licenses/by/4.0/

(c) † Open Access

\section{Abstract}

Background: Facial melanosis is a major pigmentery problem seen in the daily clinical practice. Melasma and lichen planus actinicus are among these common causes. Still some facial melanosis that had features of melasma and butterfly lichen planus actinicus but could not be classified to either of them. Objective: To evaluate melasma, lichen planus actinicus and cases that could not be classified into one or either of them using clinical picture, Wood's lump examination, and histopathological assessment. Patients and Methods: This is a case descriptive, comparative, clinical and histopathologicasl study carried out in Department of Dermatology, Baghdad Teaching Hospital, Baghdad, Iraq during the period from December 2012-May 2014. Forty patients with facial hyperpigmentation were included in this study. Twelve $(30 \%)$ were males and $28(70 \%)$ were females with female to male ratio: 2.3:1. Mean age \pm SD of studied patients was $37.07 \pm 9.63$ years. History, physical examination, Wood's lump examination and photographic pictures were done for all patients. Punch biopsy was taken from each patient, and processed and stained with Hematoxylin-Eosin (HE) and Fontana-Masson (FM) for histological evaluations. Results: These diseases were classified into: melasma with 11 patients, female to male ratio: 4.5:1 with mean age \pm SD was $33.64 \pm 6.516$ years, melasma-like lichen planus actinicus with 21 patients, female to male ratio: 2.5:1,mean age \pm SD: $39 \pm 8.349$ years, butterfly lichen planus actinicus with 8 patients, female to male ratio: $1: 1$, mean age $\pm S D: 36.75 \pm 15.088$ years. This classification depends on the following findings: some of these results could be more frequent and intense in one than others; they were the diseases of young age group, that had more tendency to affect females than males, sun light exposure and outdoor activities were the main etiological factors, but these factors were more triggering in lichen planus actinicus followed by melasma-like lichen planus actinicus and to less-

\footnotetext{
${ }^{*}$ Corresponding author.
}

How to cite this paper: Sharquie, K.E., Noaimi, A.A. and Al-Shukri, M.A. (2015) Melasma, Melasma-Like Lichen Planus Actinicus, and Butterfly Lichen Planus Actinicus Build up One Spectrum (Clinico-Histopathological Study). Journal of Cosmetics, Dermatological Sciences and Applications, 5, 212-222. http://dx.doi.org/10.4236/jcdsa.2015.53026 
er extent in melasma. The skin types were mostly III, the location and distribution of pigmentation were almost similar, Wood's lamp findings were similar although was not conclusive. The histopathological findings especially the level of melanin deposition and inflammatory infiltrate were comparable but the melanin deposition was more intense in butterfly lichen planus and melasmalike lichen planus actinicus and to lesser extent in melasma. Conclusion: From the epidemiological, clinical and histopathological findings of the present work, we can suggest a conclusion that melasma, butterfly lichen planus actinicus, and melasma-like lichen planus actinicus were inflammatory skin diseases that build up one spectrum where melasma at one pole and lichen planus actinicus at the other pole and melasma-like lichen planus actinicus at the middle. The young age group, during their active reproductive life, will have these diseases in relation to sun light exposure with seasonal variations.

\section{Keywords}

Melasam, Butterfly Lichen Planus Actinicus, Melasma-Like Lichen Planus Actinicus, Spectrum

\section{Introduction}

Facial melanosis is a major cosmetic problem among people especially in people with dark complexion and we can categorise the commonest causes of facial melanosis as follows [1]-[3].

Melasma is representing $61 \%$, frictional melanosis $12 \%$, postinflamatory hyperpigmentation $9.5 \%$, butterfly lichen planus actinicus (LPA) $8 \%$, acanthosis nigricans $7.5 \%$, nevus of Ota $1 \%$, phytophotodermatitis $0.5 \%$, gazelle eye like facial melanosis $0.5 \%$ [4].

Facial melanosis could be defined as increase in the melanin stores either in the epidermis or dermis or both as a result of increase in the number or function of melanocytes as seen in inflammatory conditions like melasma and lichen planus [5].

Although melasma and butterfly lichen planus actinicus are considered distinctive clinical entities but they share many epidemiological, clinical and histopathological features as both diseases are common in the dark skin colored peoples and especially seen in countries of Middle East [6]-[8]. Sun exposure is the main etiological triggering factors in both conditions plus other additional factors and both diseases are seen in outdoor activities with seasonal variations [6]-[9]. They are diseases of young age people with more tendency to affect females with positive family history [10] [11]. The location and distribution on the face are similar and both share the same melanin depositions in the epidermis and dermis [12]-[14].

There are some cases that are seen commonly in clinical practice share features of both melasma and butterfly lichen planus actinicus and often could not classify to either of them. Hence we think that there is a spectrum of diseases where melasma at one pole and butterfly lichen planus actinicus (LPA) at the end of the other pole and some cases lie at the middle of spectrum that have features of both diseases and deserve the name melasma-like lichen planus actinicus (MLPA).

Accordingly, the present work is arranged to support the spectrum hypothesis of these pigmentery diseases.

\section{Patients and Methods}

A case descriptive, comparative, clinical and histopathological study carried out in the Department of Dermatology and Venereology-Baghdad Teaching Hospital, Baghdad, Iraq during the period from December 2012 to May 2014.

Forty patients with facial melanosisthat had mainly butterfly distribution were enrolled in this study.

Inclusion Criteria: Patients clinically presented with facial melanosis with butterfly distribution, with no history of treatment for at least 6 months.

Exclusion Criteria: Pregnant and lactating females, patients with chronic illness like: liver, kidney, heart, blood dyscrasia, connective tissue diseases, photodermatosis, and any endocrine disease that interfere with skin pigmentation. Patients receiving drugs that involved with skin pigmentation especially female on hormonal therapy including oral contraceptive pills and immune suppressed patients. Also, patients with fascial melanosis 
that refused biopsy were not included in this study.

History was taken from each patient stressing on the followings: age, gender, onset and duration of facial melanosis, activity of the disease, history of remissions and relapses, history of seasonal variations, marital status, frictional or rubbing habits, use of cosmetics, family history of same condition, history of outdoor working, sun exposure, sunscreen applications and drug history, drug allergy, bleeding tendency, history of keloid formation after trauma or surgery. For female patients also asked about pre menstrual flare up, history of pregnancy and use of oral contraceptive pills.

All patients were photographed at first visit at fix distance with natural light source using a digital SONY16.1 MEGA PIXEL camera, The need for photos was explained to the patients. The nature and aim of this study were explained for each patient. Formal consent was taken from them before taking the biopsy, after full explanation about the nature of the disease and the study. The ethical approval was given by the Scientific Council of Dermatology \& Venereology-Iraqi Board for Medical Specializations.

All patients were examined under natural sun light for following features: distribution of rash, type of rash whether macular or papular, colour of rash, types of pigmentation either superficial so called stuck on appearance or dermal. Site of involvement, other sites of involvement apart of face were also assessed.

Wood's lamp examination done for all patients and was used to evaluate the level of melanin deposition in the skin whether epidermal, dermal or in combination.

Punch biopsy was be taken from lesional skin of the face for all forty patients using sterilized reusable stainless punch biopsy as $3 \mathrm{~mm}$ punch biopsy instrument. Each biopsy specimen was processed and stained with Hematoxylin-Eosin (HE), Fontana-Masson (FM) for histological evaluations. To evaluate the intensity of melanophages in the dermis, the following score was invented using 40 high power field on Fontana stain;

Nil: No melanophage.

Few: $(1$ - 5) from one to five melanophages.

Frequent: (6 - 15) from six to fifteen melanophages.

High number: $(16<)$ sixteen and above melanophages.

Patients were categorized into following groups depending on history and clinical pictures:

1-Typical melasma 11 patients, with brown and dark brown pigemented butterfly patches associated with histopathological features of melasma (increase epidermal melanosis, basal melanosis, dermal melanophages).

2-Typical LPA butterfly type 8 patients, with gray brown pigmented butterfly like configuration patches associated with histopathological features of LPA (orthokeratosis, hypergranulosis, irregular acanthosis, vacuolar alteration of the basal layer, and a band like dermal melanosis.

3-An overlap cases 21 patients with facial melanosis that had melasma-like distribution but the pigmentation was mainly brown, dark brown, red brown, and gray brown in color and hands could be involved and couldn't be categorized clinically as LPA or melasma. Also, the histopathological picture was more in favor LPA.

Data were statistically described in term range, mean, stander deviation $( \pm \mathrm{SD})$, and frequencies (number of cases) and relative frequencies (percentages). Comparison between different groups in the present study was done using Chi square test. Fisher's Exact Test was used when one of the cells in the table has zero value. A probability value (P value) less than 0.005 was considered significant. All statistical calculations were done using computer statistical programs SPSS ver.20 (Statistical Package for the Social Science; SPSS Inc. Chicago, IL, USA).

\section{Results}

Forty patients with facial hyperpigmentation were included in this study, twelve (30\%) were males and 28 (70\%) were females with female to male ratio (2.3:1). The mean age \pm SD of studied patients was $37.07 \pm 9.63$ years. Patients were categorized into following groups depending on history and clinical pictures:

1 -Typical melasma 11 patients.

2-Typical LPA butterfly type 8 patients.

3-Melasma-like lichen planus actinicus (MLPA) 21 patients with facial melanosis that had melasma-like distribution but the pigmentation was mainly brown, dark brown, red brown, and gray brown in color and hands could be involved and couldn't be categorized clinically as LPA or melasma. Also, the histopathological picture was more in favor LPA. 


\subsection{Melasma}

Clinical study: All 11 patients were of skin type III, with female to male ratio (4.5:1), the mean age \pm SD was $33.64 \pm 6.516$ years. One $(9.1 \%)$ patient had pruritus. Color of the lesions were brown in all patients. Three (27.3\%) patients were outdoor workers with sun exposure at mid-day for more than 3 hours, 4 (36.4\%) patients had positive family history for the same problem. In addition 4 (36.4\%) patients had positive family history of LP. Morphological forms of skin lesions were observed as macular/patch with stuck on like appearance in all patients. Also, patients had butterfly distribution. Three (27.3\%) patients had a seasonal exacerbation of their skin lesions during summer and spring especially at April and August. Wood's light examination showed that 7 (63.6\%) patients had epidermal lesions, 3 (27.3\%) dermal and one (9.1\%) mixed (Figure 1(a)).
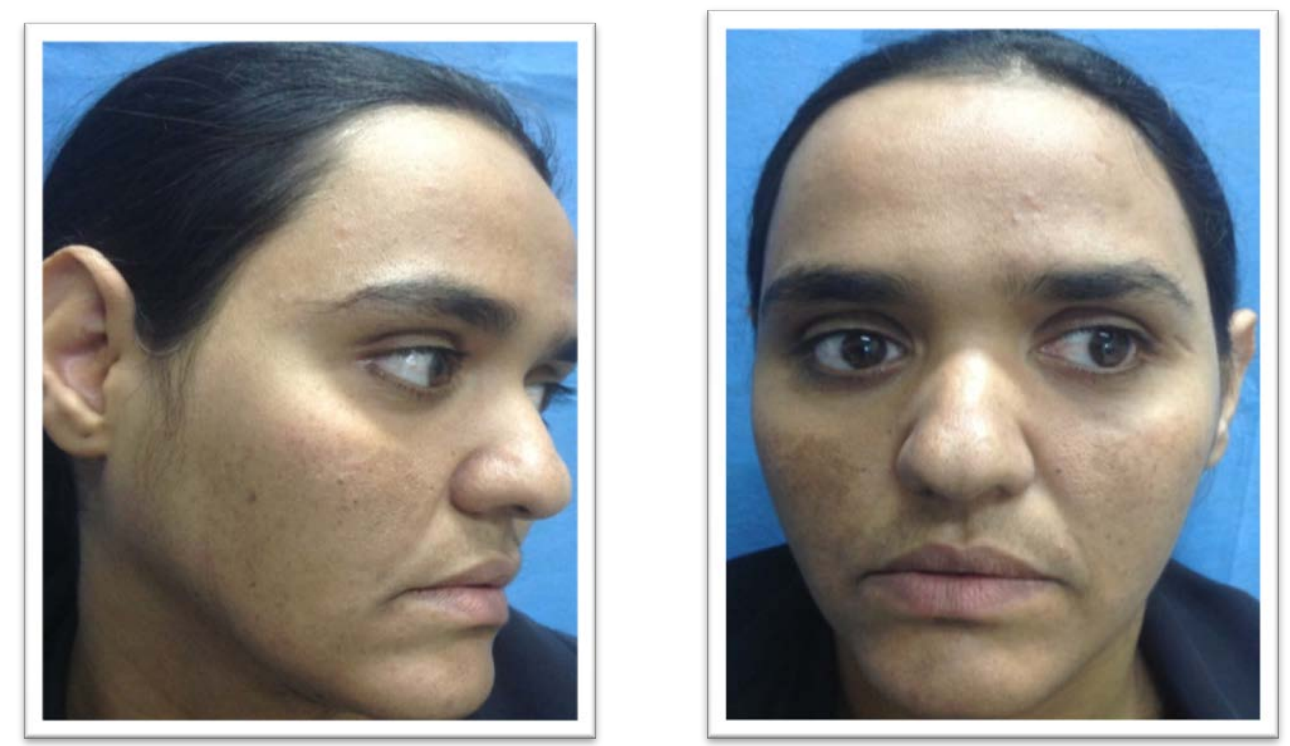

(a)

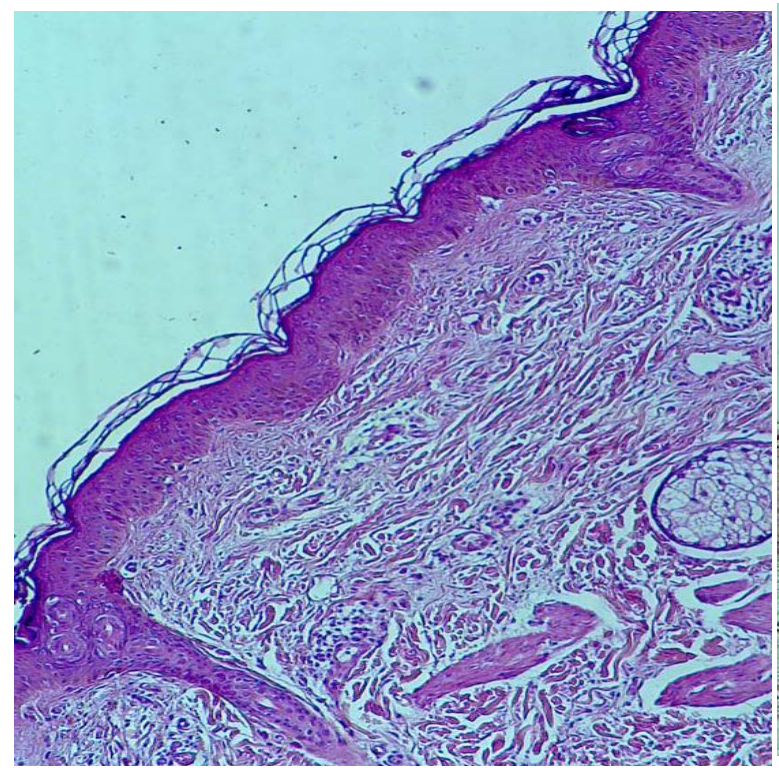

(b)

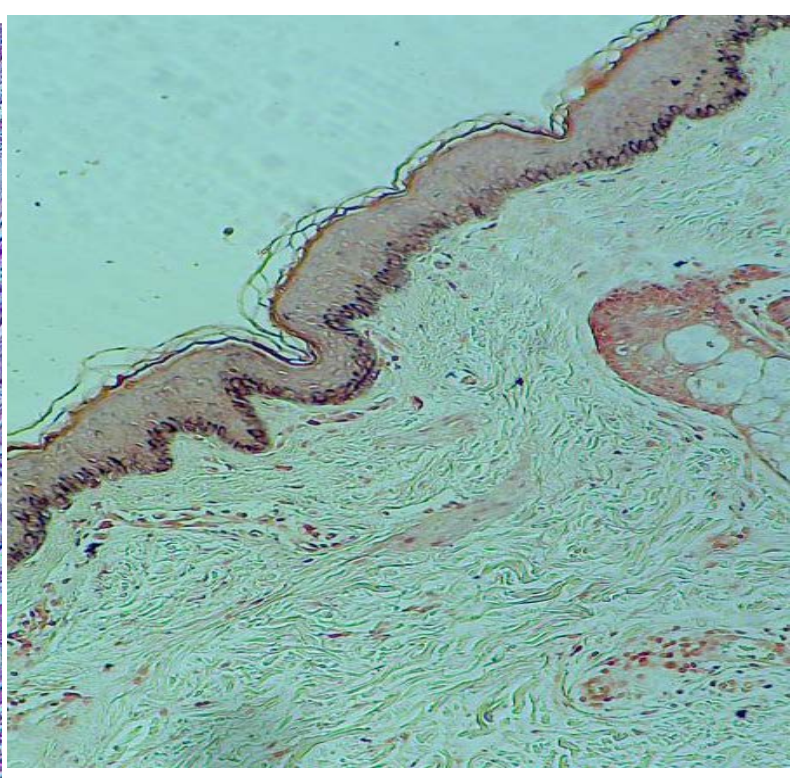

(c)

Figure 1. (a) Twenty eight years old female with typical picture of butterfly melasma; (b) H \& E stain $\times 10$; (c) Fontana Stain $\times 10$. (b) (c) Histopathological pictures of melasma showing basal melanosis with few dermal melanophages with sparse perivascular lymphocytic infiltrate. 
H \& E Stain: All patients with melasma had normal epidermis. Basal liquefaction were not present in all patients while basal melanosis were present in 10 (90.9\%) patients. Ten (90.9\%) patients had sparse superficial perivascular lymphocytic infiltrate and one (9.1\%) had no infiltrate. Five (45.45\%) patients had no melanophages in the dermis, 5 (45.45\%) had few and one (9.1\%) had frequent melanophages (Figure 1(b)).

Fontana Stain: Basal melanosis were presented in 10 (90.9\%) patients, dermal melanophages seen in five (45.5\%) as few dermal melanophages and 5 (45.5\%) patients had frequent melanophages (Figure 1(c)).

Wood's light examination was statistically different from histopathology in identifying depth of pigment in melasma $(P$ value $=0.032)$.

\subsection{Lichen Planus Actinicus}

Clinical study: Six (75\%) out of 8 patients had skin type III while 2 (25\%) skin type IV, with female to male ratio (1:1) The mean age \pm SD was $36.75 \pm 15.088$ years. All patients $(100 \%)$ had pruritus. One (12.5\%) patient had lesion with brown color, one (12.5\%) gray brown and 6 (75\%) red brown skin lesions. Seven (87.5\%) patients were outdoor workers. One (12.5\%) patient had positive family history of LPA while 2 (25\%) patients had positive family history of melasma. Six (75\%) patients had macular/patch lesions and 2 (25\%) had maculopapular form. Six (75\%) patients had butterfly-like lesions while 2 (25\%) had mask like distribution of lesion. All patients had seasonal exacerbation. Wood's light examination showed that 2 (25\%) patients had epidermal lesions, 4 (50\%) dermal and 2 (25\%) mixed (Figure 2(a)).

H \& E Stain: Five (62.5\%) patients had thin epidermis while 3 (37.5\%) had acanthosis with hypergranulosis. Focal basal liquefaction was seen in 2 (25\%) patients and were diffuse in 4 (50\%) patients. Basal melanosis present in 4 (50\%) patients. Three (37.5) had sparse infiltrate and 5 (62.5\%) had band like infiltrate. Four (50\%) patients had few melanophages and 4 (50\%) had frequent melanophages (Figure 2(b)).

Fontana Stain: Basal melanosis were presented in 4 (50\%) patients. Three (37.5) patients had sparse infiltrate and 5 (62.5\%) had band like infiltrate. Four (50\%) patients had frequent melanophages while 4 (50\%) had high numbers of melanophages (Figure 2(c)).

Wood's light examination was statistically not different from histopathology in identifying depth of pigment in LPA (P value= 0.264).

\subsection{Melasma-Like LPA}

Clinical study: Fifteen (71.4\%) out of 21 patients had skin type III, while 3 (14.3\%) had skin type II and other $3(14.3 \%)$ had skin type IV, with female to male ratio $(2.5: 1)$, the mean age \pm SD was $39 \pm 8.349$ years. Seventeen (81\%) patients had pruritus. The skin lesions were gray brown 10 (47.6\%), brown in 6 (28.6\%) patients, red brown in 3 (14.3\%), and dark brown in 2 (9.5\%) patients. Twelve (57.1\%) patients were outdoor workers. Five (23.8\%) patients had positive family history of LPA while 8 (38.1\%) patients had positive family history of melasma. Sixteen (76.2\%) patients had macular/patch lesions and 5 (23.8\%) had maculopapular form. Nine (42.95) patients had butterfly distribution, 6 (28.6\%) on forehead, 4 (19\%) had butterfly plus lesions on dorsa of hand and forearm and 2 (9.5\%) had mask like distributions plus lesions on dorsa of hand and forearm. Seventeen (81\%) patients had seasonal exacerbation. Wood's light examination showed that 6 (28.6\%) patients had epidermal lesions, 13 (61.9\%) dermal and 2 (9.5\%) mixed (Figure 3(a)).

H \& E Stain: Thirteen (61.9\%)patients had thin epidermis, 7 (33.3\%) patients had normal epidermis, and one (4.8\%) acanthosis. Four (19\%) patients had focal and 5 (23.8\%) had diffuse basal liquefaction. Basal melanosis was present in 16 (76.2\%) patients. Twelve (57.1\%) patients had sparse lymphocytic infiltrate and 9 (42.9\%) had band infiltrate. Eight (38.1\%) patients had few melanophages and 13 (61.9\%) had frequent melanophages (Figure 3(b)).

Fontana stain: Basal melanosis was seen in 16 (76.2\%) patients. Twelve (57.1\%) patients had sparse infiltrate and 9 (42.9\%) had band infiltrate. Three (14.3\%) patients had few melanophages, while 5 (23.8\%) had frequent melanophages and 13 (61.9\%) had high score of melanophages (Figure 3(c)).

Wood's light examination was statistically different from histopathology in identifying depth of pigment in MLPA (P value $=0.001)$.

Comparison between the three group of facial melanosis many common things were noticed in the clinical findings and histopathological pictures including H \& E and Fontana stains (Tables 1-4 and Figure 4). 
Table 1. Most common clinical findings between the 3 groups.

\begin{tabular}{cccc}
\hline Demographic data & Melasma & LPA & MLPA \\
\hline Gender ( ${ }^{\top}:$ ratio) & $1: 4.5$ & $1: 1$ & $1: 2.5$ \\
Skin type III & $100 \%$ & $75 \%$ & $71.4 \%$ \\
Skin color & Brown $(100 \%)$ & Gray Brown (75\%) & Gray Brown (47.6\%) \\
Pruritus & $(9.1 \%)$ & $(100 \%)$ & $(81 \%)$ \\
Outdoor & $(27.3 \%)$ & $(87.5 \%)$ & $(57.1 \%)$ \\
Family history of same condition & $(36.4 \%)$ & $(12.5 \%)$ & $(23.8 . \%)$ \\
Family history of other condition & $36.4 \%$ & $(25.0 \%)$ & $(78.1 \%)$ \\
Type of lesion (Macular) & $(90.9 \%)$ & $(75 \%)$ & $42.9 \%$ \\
Distribution of lesion (Butterfly) & $100 \%$ & $87.5 \%$ & $(81 \%)$ \\
Seasonal exacerbation & $(27.3 \%)$ & $(100 \%)$ & $(76)$ \\
\hline
\end{tabular}
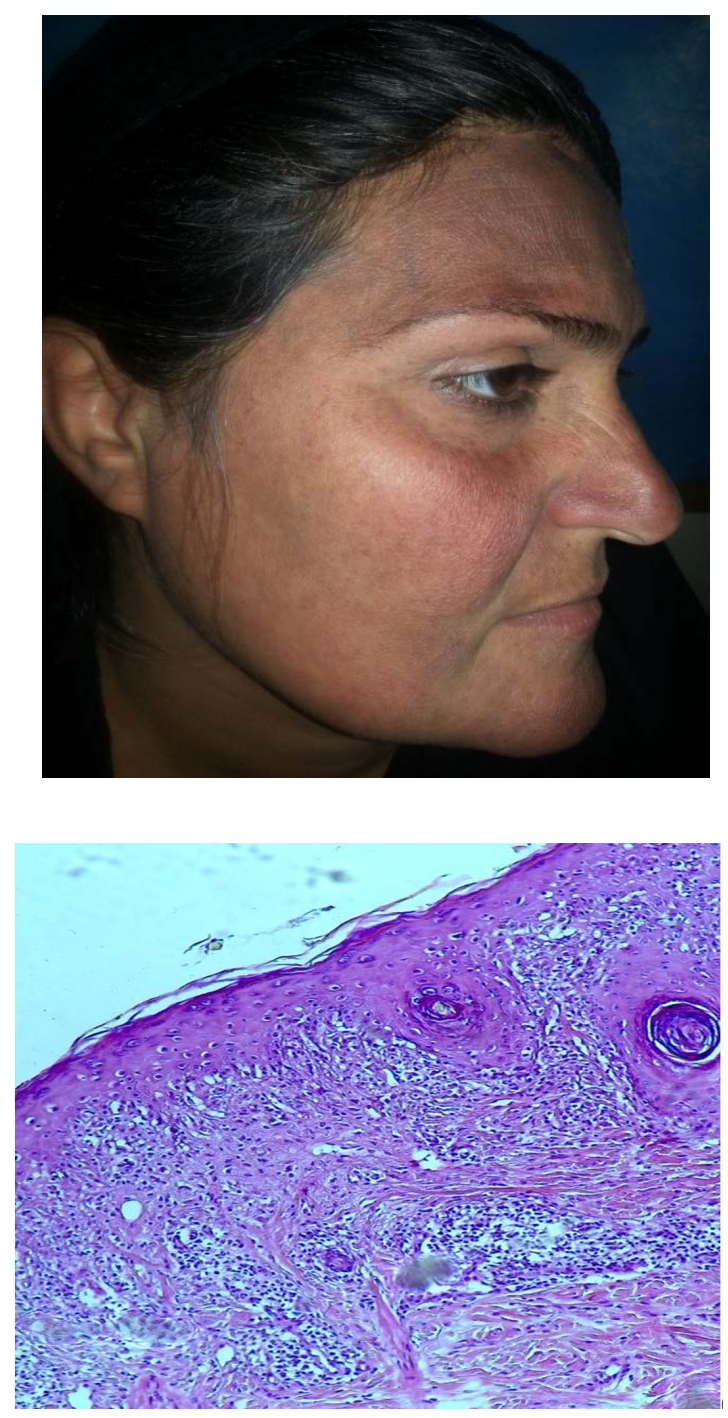

(b)

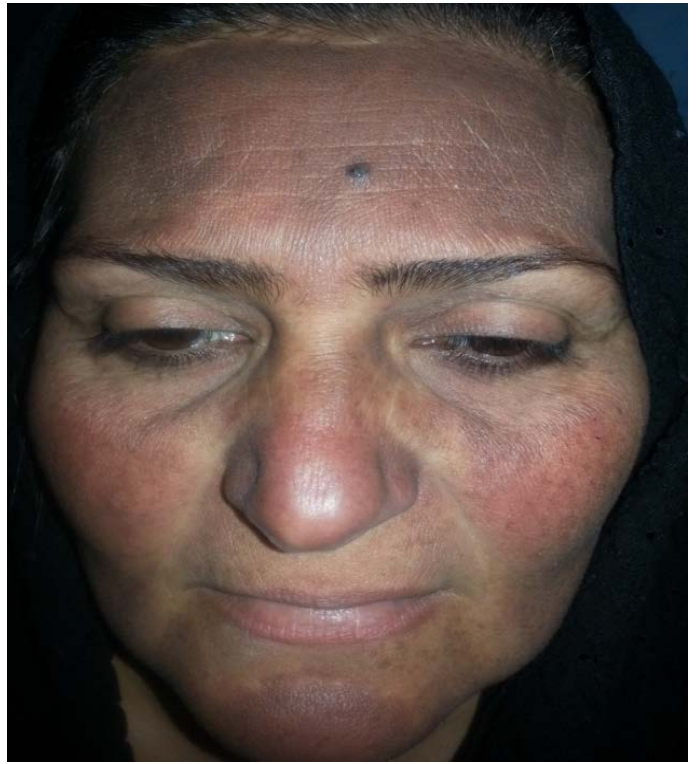

(a)

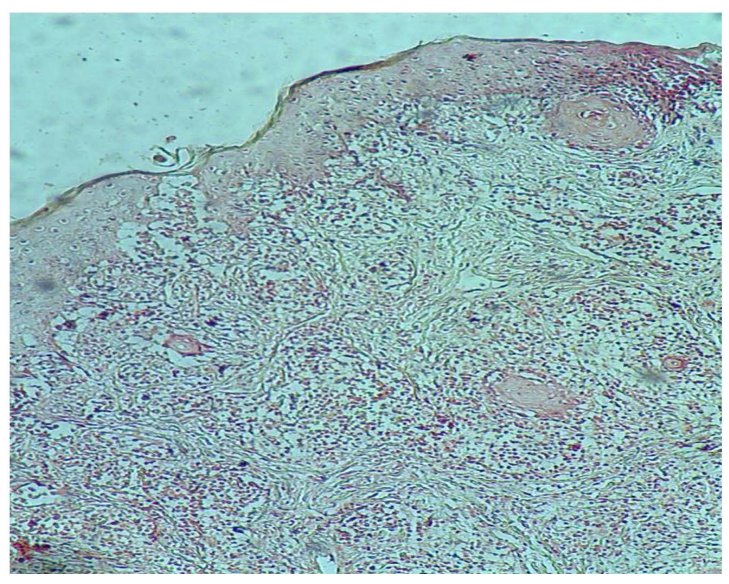

(c)

Figure 2. (a) Thirty eight years old female with melasma mask like lichen planus actinicus; (b) HE Stain $\times 10$; (c) Fontana Stain $\times 10$; (b) (c) Histopathological pictures showing acanthosis, basal liquefaction with marked perivascular infiltrate admixed with many melanophages. 
Table 2. The most common histopathological (H \& E stain) findings between the 3 groups.

\begin{tabular}{cccc}
\hline Histopathology by H \& E stain & Melasma \% & LPA \% & MLPA \% \\
\hline Epidermal changes & $0 \%$ & $(62.5 \%)$ & $(61.9 \%)$ \\
Basal liquefaction & $0 \%$ & $(50.0 \%)$ & $(23.8 \%)$ \\
Basal melanosis & $(90.9 \%)$ & $(50.0 \%)$ & $(76.2 \%)$ \\
Dermal cell infiltrates & $(90.9 \%)$ & $(100 . \%)$ & $(100 \%)$ \\
Intensity of melanophages & $(45.45 \%)$ & $(100 \%)$ & $(100 \%)$ \\
Level of pigmentation & Mixed & Mixed & Mixed \\
\hline
\end{tabular}
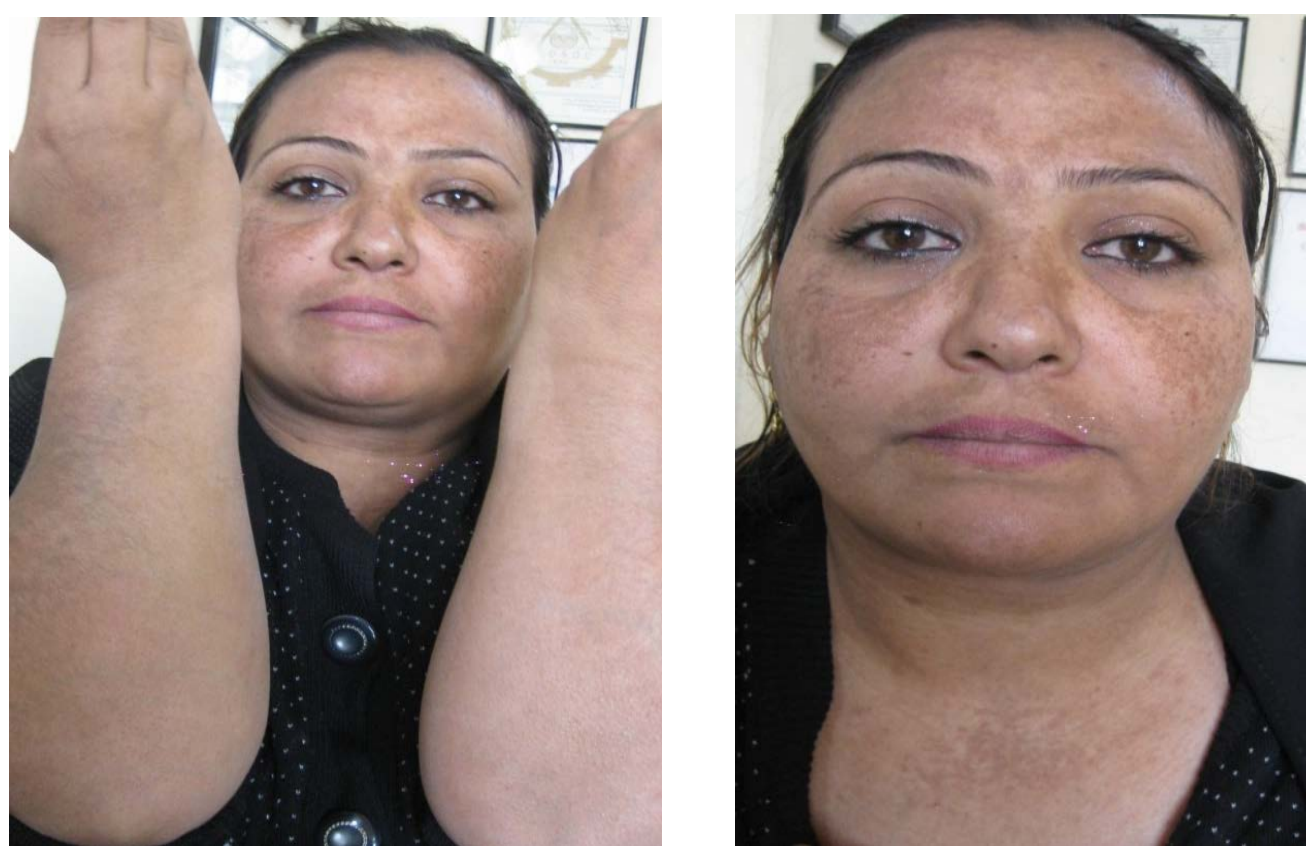

(a)

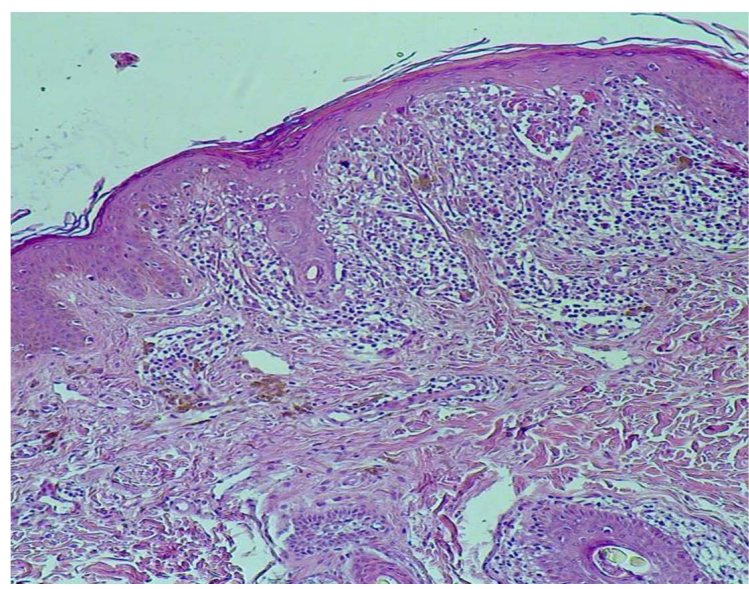

(b)

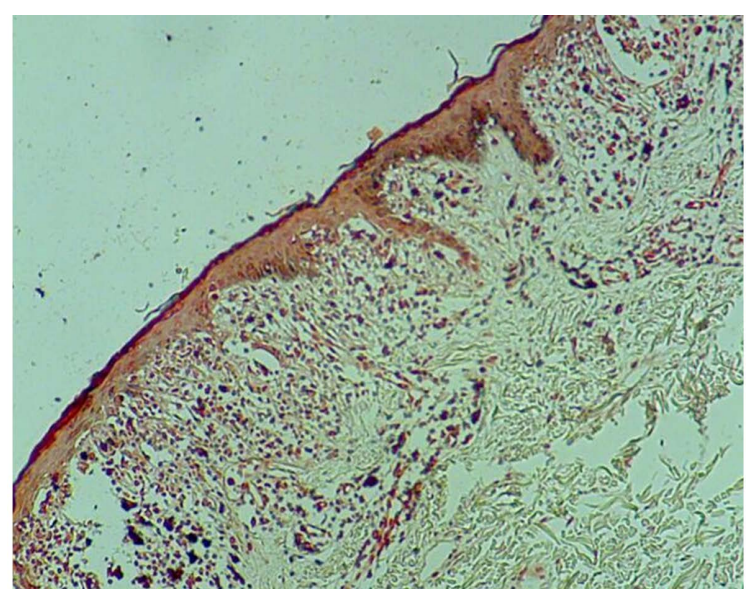

(c)

Figure 3. (a) Thirty four years old female showing butterfly melasma-like lichen planus actinicus with involvement of dorsa of both hands and V-area of chest; (b) H \& E Stain $\times 10$; (c) Fontana Stain $\times 10$; (b) (c) Histopathological pictures showing features of melasma-like lichen planus actinicus like hypergranulosis, acanthosis, basal liquefacation, band infiltrate of lymphocyte with high number of melanophages. 
Table 3. The most common histopathological findings between the 3 groups using Fontana stain.

\begin{tabular}{cccc}
\hline Histopathology by Fontana stain & $\begin{array}{c}\text { Melasma } \\
\%\end{array}$ & $\begin{array}{c}\text { LPA } \\
\%\end{array}$ & $\begin{array}{c}\text { MLPA } \\
\%\end{array}$ \\
Basal melanosis & $90.9 \%$ & $50.0 \%$ & $76.2 \%$ \\
Melanophages & $(45.45 \%)$ & $(100 \%)$ & $(100 \%)$ \\
Level of pigmentation & $\begin{array}{c}\text { Mixed } \\
\text { Mixed }\end{array}$ & $\begin{array}{c}\text { Mixed } \\
(63.6 \%)\end{array}$ \\
\hline
\end{tabular}

Table 4. Comparison between Woods's light and histopathological findings regarding the level of pigmentation in patients in all groups.

\begin{tabular}{|c|c|c|c|c|c|c|c|c|}
\hline \multirow{2}{*}{\multicolumn{2}{|c|}{ Depth of pigmentation }} & \multicolumn{2}{|c|}{ Melasma } & \multicolumn{2}{|c|}{ LPA } & \multicolumn{2}{|c|}{ MLPA } & \multirow{2}{*}{ P-value } \\
\hline & & $\mathrm{N}$ & $\%$ & $\mathrm{~N}$ & $\%$ & $\mathrm{~N}$ & $\%$ & \\
\hline \multirow{3}{*}{ Wood's light } & Epidermal & 7 & $63.6 \%$ & 2 & $25.0 \%$ & 6 & $28.6 \%$ & \multirow{3}{*}{0.217} \\
\hline & Dermal & 3 & $27.3 \%$ & 4 & $50.0 \%$ & 13 & $61.9 \%$ & \\
\hline & Mixed & 1 & $9.1 \%$ & 2 & $25.0 \%$ & 2 & $9.5 \%$ & \\
\hline \multirow{3}{*}{$\begin{array}{l}\text { Histopathology } \\
\text { H\&E stain }\end{array}$} & Epidermal & 5 & $45.5 \%$ & 0 & $0.0 \%$ & 0 & $0.0 \%$ & \multirow{3}{*}{0.001} \\
\hline & Dermal & 0 & $0.0 \%$ & 4 & $50.0 \%$ & 6 & $28.6 \%$ & \\
\hline & Mixed & 6 & $54.5 \%$ & 4 & $50.0 \%$ & 15 & $71.4 \%$ & \\
\hline
\end{tabular}
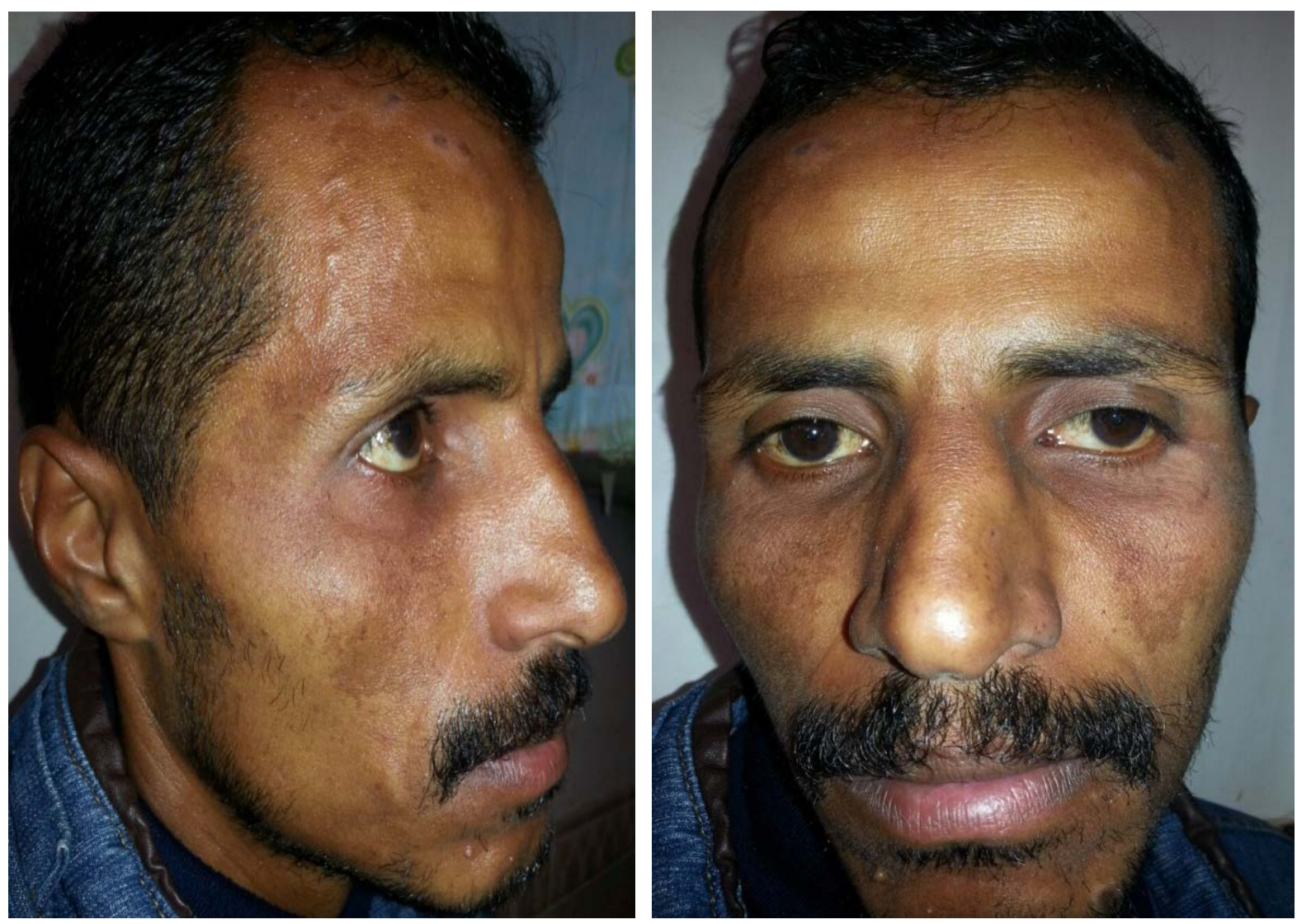

Figure 4. (a) Thiry six years old male showing clinical feature of annular LPA on the forehead with melasma features on both cheecks. 


\section{Discussion}

Facial melanoses are group of facial pigmentation where there is increase of skin melanin whether epidermal or dermal and these disorders are major health problems in Iraqi population [6] [10]. Melasma and facial LPA constitute the main causes of facial melanosis where the sun light is the main etiological factor involved in their etiopathogenesis [4].

During our daily clinical practice, we see cases that are similar to melasma but there is clinical and histopathological difference. In addition we see cases where they have melasma in winter time but change to LPA in summer time. These observations encouraged us to conduct the present work where three group of diseases are classified: classical melasma, classical facial LPA butterfly type, and cases where couldn't categorized into melasma or LPA were evaluated by clinical and HP studies so called MLPA.

The present study showed many similarities between these three diseases and from these similarities we can draw spectrum where melasma at one end and LPA in other end while MLPA is in the middle (Figure 5).

Age is comparable as these diseases affect young age group in their active reproductive life, such as melasma: mean age \pm SD was $(33.64 \pm 6.516)$, LPA mean age \pm SD $(36.75 \pm 15.088)$ while MLPA had mean age \pm SD (39 \pm 8.349). Females are mainly affected in melasma (female to male ratio 4.5:1) and in MLPA (female to male ratio 2.5:1), while in LPA gender was equal. Family history was positive for the same disease in all three groups as in melasma (36.4\%), in MLPA (23.8\%), and LPA (12.5\%).Outdoor activity was more frequent in LPA 87.5\% and MLPA 57.1\%, while in melasma 27.3\%. The rash was macular in melasma (100\%) but in MLPA was macular in $76.2 \%$ and papular in $23.8 \%$ of cases while in LPA was macular in $75 \%$ and papular in $25 \%$ of patients. Itching might occur in all three diseases but in different frequency such as in melasma (9.1\%), MLPA (81\%), and in LPA (100\%).

In the three groups of these diseases, there are two sharing etiological factors mainly they are a disease of active reproductive life and sharing sun light exposure with outdoor activities. Somebody might raise question: what are the role of sex hormones especially during pregnancy in the etiopathogenesis of melasma. It is difficult to answer this question but we can speculate that sex hormones mainly estrogen and progesterone might act as cofactors like by sensitising the skin to sun light action in females patient and even in males.

In the present study, families were seen where one sister had melasma while the other sister had LPA or MLPA. Also, patient with melasma had positive family history of LPA (36.4\%), while MLPA patients had positive family history of melasma (38.1), and LPA patients had positive family history of melasma (25\%). Seasonal variation was noticed in all three diseases where there was a seasonal exacerbation in summer time but mainly in

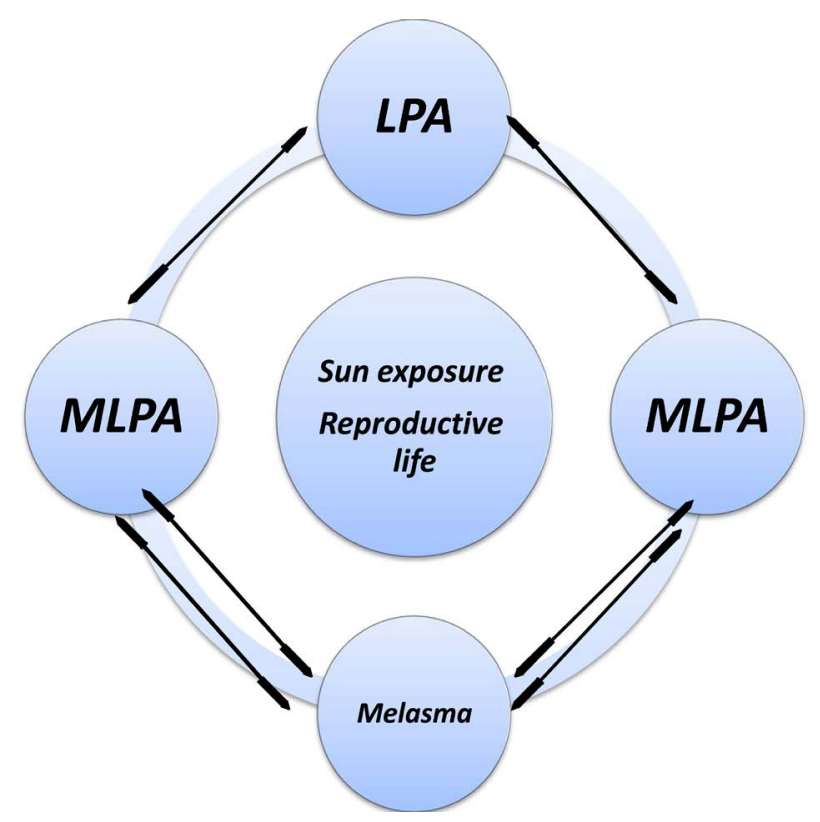

Figure 5. Showing the spectrum and the overlap between melasma, MLPA, butterfly LPA. 
April and September and decline in winter time as in melasma showed exacerbation in (27.3\%), in MLPA (81\%), and in LPA was (100\%). Some patients with LPA or MLPA might change into ordinary melasma in winter time and change into LPA in summer time while some cases of melasma might change into into LPA or MLPLA in summer time.

Skin types were found almost similar as skin type III in melasma was (100\%), while in MLPA (71.4\%), and in LPA (75\%). The color of the rash is variable but in general was brown in melasma (100\%), gray brown in MLPA (47.6\%), and red brown in LPA (75\%).

Distribution of rash was similar in these three groups usually sharing butterfly distribution like in melasma (100\%), in MLPA (42.9\%), and in LPA (75\%), even could be mask type in LPA (25\%), MLPA (9.5\%). Extra facial rash were noticed on the hand, forearm, and V area of the chest in MLPA (28.5\%) and some cases of LPA.

Wood's lump examination was variable but usually in melasma showed epidermal pigmentation in (63.6\%), while in MLPA was dermal pigmentation in (61.9), and in LPA was dermal melanosis in (50\%). But there was major controversy between Wood's lump examination and histopathological examination as seen in Table 4 . Accordingly Wood's lump examination is not a good predictive test to asses depth of melanin deposition in skin.

By histopathologial evaluation using HE stain, lymphocytic infiltrate was mild in melasma, moderate in MLPA, and severe in LPA. Basal liquefaction was nil in melasma, while present in LPA ((75\%) and in MLPA was (42.9\%). In addition basal melanosis was positive in all three groups. While dermal melanophages by HE stain were seen in melasma 45.5\%, MLPA (100\%), and in LPA (100\%). But in all groups, Fontana stain showed great discrepancy with HE stain as melanophages few by HE stain while was frequent or high by Fontana stain, but in general there were few in melasma frequent in MLPA and high in number in LPA. When the results of three groups were compared with each other, we can draw a diagram as seen in Figure 5 showing the overlap of these three groups with each other that could change to another group according to season and severity of sun light exposure.

\section{Conclusions}

$\checkmark$ Melasma, LPA, and MLPA are important causes for facial melanosis and they affect mainly female patients in the same age group mostly during reproductive age with a similar skin type which is type III. Also they have the same distribution of rash mainly facial butter fly.

$\checkmark$ These three diseases are sharing the history of sun exposure, and seasonal exacerbation in summer time which give a clue for the same etiological factors.

$\checkmark$ Positive family history was seen in all three diseases for the same diseases and also positive family history for each other.

$\checkmark$ All these three diseases are inflammatory in nature as seen by histopathological study in a form of superficial perivasculer lymphocytic infiltrate with basal melanosis and dermal pigmentations as dermal melanophages were seen in all these groups.

$\checkmark$ Wood's lump examinations are not dependable test to assess the depth of pigmentations whether epidermal or dermal in all groups.

$\checkmark$ From clinical and histopathological findings of the present work, we can give a debatable conclusion that melasma, LPA, and MLPA could form a spectrum of diseases as melasma at one end of spectrum and butterfly LPA at the other end while MLPA lie at the middle of spectrum.

\section{Disclosure}

This study was an independent study and not funded by any drug companies.

\section{References}

[1] Anstey, A.V. (2010) Disorders of Skin Colour. Rook’s Textbook of Dermatology. 8th Edition, Wiley-Blackwell Publishing Company, Singapore, 2923-2982.

[2] Chang, M.W. (2012) Disorders of Hyperpigmentation. Dermatology Jean L Bolognia, 3rd Edition, Elsever Saundres, 1052-1053.

[3] Pandya, A.G. and Guevara, I.L. (2000) Disorders of Hyperpigmentation. Dermatologic Clinics, 18, 91-98. 
http://dx.doi.org/10.1016/S0733-8635(05)70150-9

[4] Sharquie, K.E. and Noaimi, A.A. (2014) Gazelle Eye Like Facial Melanosis (Clinico-Histopathological Study). Journal of Pigmentary Disorders, 2, 111.

[5] Sharquie, K.E., Noaimi, A.A. and Al-Ogaily, S.M. (2015) Acanthosis Nigricans as a Cause of Facial Melanosis (Clinical and Histopathological Study). IOSR Journal of Dental and Medical Science, in Press.

[6] Mohammad, K.I. (1989) Melasma in Iraq. Clinical and Epidemiological Study. A Diploma Dissertation in Dermatology and Venereology, College of Medicine, University of Baghdad, Baghdad.

[7] Sharquie, K.E. and Dhahir, S.A. (2000) Melasma in Iraqi Women, a Clinical, Histopathological and Histochemical Study. Journal of Pan-Arab League of Dermatologists, 3, 111-117.

[8] Tetsuo, S. and Yoko, K. (2012) Lichen Planus and Lichenoid Dermatoses. In: Bolognia, J.L., Jorizzo, J.L. and Schaffer, J.V., Eds., Dermatology Jean L Bolognia, 3rd Edition, Elsever Saundres, 183-195.

[9] Al-Waiz, M.M. (1999) Lichen Planus among IRAQI Patients a Clinico-Epidemiological Study. Iraqi Journal Community Medicine, 12, 63-66.

[10] Al-Waiz, M.M. (1999) Treatment of Lichen Planus Actinicus by PUVA Therapy. Iraqi Journal Community Medicine, 12, 55-57.

[11] Lattif, E.A. (1991) Lichen Planus Actinicus among Iraqi Patients. A Diploma Dissertation in Dermatology \& Venereology, College of Medicine, University of Baghdad, Baghdad.

[12] Kang, W.H., Yoon, K.H., Lee, E.S., Kim, J., Lee, K.B., Yim, H., Sohn, S. and Im, S. (2002) Melasma: Histopathological Characteristics in 56 Korean Patients. British Journal of Dermatology, 146, 228-237. http://dx.doi.org/10.1046/j.0007-0963.2001.04556.x

[13] Salman, M.S., Kibbi, A.G. and Shukrallah, Z. (1989) Actinic Lichen Planus. Aclinicopathologic Study of 16 Patients. Journal of American Academy Dermatology, 20, 226-231. http://dx.doi.org/10.1016/S0190-9622(89)70026-8

[14] Parihar, A., Sharma, S., Bhattacharya, S.N. and Singh, U.R. (2014) A Clinicopathological Study of Cutaneous Lichen Planus. Journal of the Saudi Society of Dermatology \& Dermatologic Surgery, 12, 1. 